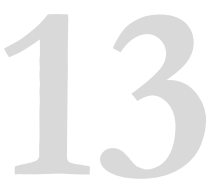

\title{
Adaptation and the question of migration: Directions in dealing with climate change in Kiribati
}

\author{
Elfriede Hermann and Wolfgang Kempf
}

\begin{abstract}
In this chapter, we look at the central Pacific atoll state of Kiribati, which is considered particularly vulnerable to the consequences of climate change but is also characterized by its citizens' emphasis of their potential for resilience. We argue that the inhabitants' cultural conception of land and imaginations of the future influence how citizens and policymakers deal with adaptation and the question of migration. We show that in the past two decades, when Kiribati was confronted with scientific projections on the likely effects of climate change, two successive governments pursued different politics of hope. In turning to discourses of Kiribati's citizens, we trace their express will to adapt and their responses to the question of migration. Most of Kiribati's citizens have articulated this will by staying on the land, while a minority have considered the option of future collective relocation when the former Kiribati government bought a large piece of land in the state of Fiji. We conclude that the cultural conception of land and imaginations of the future significantly influence the directions that adaptation and/or migration might take, whether government policies and local discourses envisage staying in Kiribati or seeking a home outside the state territory.
\end{abstract}

Cite this article: Hermann, E. \& Kempf, W. (2019): Adaptation and the question of migration: Directions in dealing with climate change in Kiribati. In: Klöck, C. \& Fink, M. (eds.): Dealing with climate change on small islands: Towards effective and sustainable adaptation? (pp. 293-312). Göttingen: Göttingen University Press. https://doi.org/10.17875/gup2019-1221 


\section{$1 \quad$ Introduction}

Atoll countries stand out from other Small Island Developing States (SIDS) because they are considered particularly vulnerable to the consequences of climate change due to the low and small land areas of their islands, the resulting limited resources of drinking water and cultivation opportunities, and the relatively high population density and low income of their populations (Barnett \& Adger, 2003, p. 322; Nunn, 2009, pp. 227-228; Barnett \& Campbell, 2010; Nurse et al., 2014; Barnett, 2017, p. 4). Vulnerability, however, is countered by the adaptive abilities and social resilience of atoll inhabitants. A lot more empirical research is needed on the potentials that inhabitants of atolls and other SIDS possess (e.g. Barnett \& Adger, 2003, p. 328; Mortreux \& Barnett, 2009, p. 105; Barnett \& Campbell, 2010; Lazrus, 2012; Barnett, 2017, pp. 10-11). In view of scientific projections about the future impacts of climate change, governments and citizens in atoll countries face the challenge of deciding which adaptation measures to take. Essentially, measures of in situ adaptation have to be distinguished from migration as adaptation. On the one hand, technological and management options are available for in situ adaptation (Nunn, 2009, pp. 221-227). On the other hand, politicians, media, scientists, and citizens have discussed different types of migration (e.g. Kempf, 2009; Betzold, 2015). One type of migration as adaptation to climate change is voluntary labour migration (Barnett \& Chamberlain, 2010; Barnett \& Webber, 2010; Barnett \& O’Neill, 2012). Another type is relocation (Nunn, 2009, pp. 227-228), and a distinction is made here between internal versus international relocation (Campbell, 2010a, 2010b; Campbell \& Bedford, 2014). Which adaptation measures can be taken always depends on the possibilities of financing, not only through national funds but also through external donors (Betzold, 2015, 2016). Moreover, limitations on adaptation result from the structural problem of power asymmetry between international donors and recipients in the small island states (Barnett \& Campbell, 2010; Betzold, 2015, 2016; Barnett, 2017, p. 7).

Kiribati is one of five atoll countries in the world, four of which are sovereign states (e.g. Barnett \& Adger, 2003, p. 322). It became the Republic of Kiribati in 1979 and comprises 33 islands located in the central Pacific region. Of these islands, 32 are low-lying atolls or reef islands, which rise to only about $3 \mathrm{~m}$ above sea level; the other, Banaba, is a raised limestone island, on which phosphate was mined (Neemia \& Thaman, 1993, p. 288; Storey \& Hunter, 2010, p. 168). Discourses on global warming that have reached Kiribati have drawn attention to rising sea levels, the increase in extreme weather events, and other threatening consequences (Neemia \& Thaman, 1993, p. 295). Such discourses circulated on the islands of Kiribati with varying intensity during the first two decades of the $21^{\text {st }}$ century. Representatives of the state, the internationally financed adaptation programmes, international and national non-governmental organizations (NGOs) and initiatives, churches and media, and committed individuals contributed to the dissemination of these discourses. Subsequently, some citizens of Kiribati, the 
I-Kiribati, began to perceive changes as the effects of climate change, as Neemia Mackenzie (2004) observed. On the whole, the spectrum of reception ranges from a rejection of climate change discourses to intensive discussion of the relevant knowledge (Kempf, 2017; Hermann \& Kempf, 2018, pp. 21-22).

In this chapter, we explore which adaptation measures - including migration as adaptation - have been discussed, targeted, and taken in Kiribati over the past two decades. From a cultural and social anthropological perspective, we try particularly to understand the cultural logics that guide the I-Kiribati in their efforts to adapt to the consequences of climate change. We argue that the cultural conception of land and imaginations of the future influence how citizens and policymakers deal with adaptation and the question of migration. In cultural terms, land - especially because of the understanding that people belong to land - is the basis of the existence of interrelated human and non-human entities throughout time (Hermann, 2017). In Kiribati, land is the basis for an existential security in the world that has been established in the past, is perceptible in the present, and is presupposed for the future. With the components of people belonging to the land and the identification that goes with it, the Kiribati concept of land resembles the meanings of land in other Pacific Island societies (Campbell, 2010b, pp. 60-64). Carol Farbotko (this volume), also looking at communities in Oceania, explains that land is crucial to Pacific Islanders' ontological security. She adopts the concept of ontological security from Kinnvall and Mitzen (2017), who call it a sense of security that political subjects have when they can presuppose biographical continuity and wholeness recognised by others (Kinnvall \& Mitzen, 2017, p. 4). If we see 'ontological' here in a very comprehensive sense as being in connection with the environment and cosmos and the spiritual powers invigorating them, then it can also be said for Kiribati that land contributes to such security. In combination with land concepts, discourses on the future play an important role in adaptation planning and action. "Adaptation is about changes to secure futures and so carries with it a precondition that there is a future to be secured," as Barnett $(2017$, p. 7) very aptly wrote. With Appadurai (2013), we would like to add that the future is culturally made. We, therefore, see adaptation measures in relation to cultural discourses that actors have adopted as their own. Atoll states follow specific "justifiable logics" (Barnett, 2017, p. 9) in their approaches to adaptation. From our point of view, these logics are culturally shaped. Concepts of land - with their component of people belonging to land - and ideas of the future play a significant role in these cultural logics.

A variety of adaptation strategies is pursued in Kiribati: both in situ adaptation and migration as adaptation. Depending on the respective political context, one or the other type is emphasised more strongly, but both types are often addressed in the sense of "transformational adaptation" (see Nunn and McNamara, this volume), i.e. as a response that is transformational in the longer term. Regarding in situ adaptation, the Kiribati Adaptation Program (KAP) has to be especially mentioned since it was a large-scale aid-driven adaptation program and the first to be launched in the atoll state (e.g. Government of the Republic of Kiribati, 2013; Storey \& 
Hunter, 2010; Kempf \& Hermann, 2014, p. 201; Prance, 2016; Barnett, 2017, p. 7). In the course of the KAP that began in 2003 and came to an end in 2018, measures have been taken for coastal protection, securing fresh water resources, and fortifying infrastructure. In addition, further options, such as the elevation of some areas, have been and are being explored. If migration is discussed as an adaptation strategy in Kiribati, then it is, on the one hand, about labour mobility with the option of return but, on the other hand, also about resettlement as a last resort.

In our efforts to analyse discourses and measures of adaptation, we devise the concept of 'direction'. We use the term direction as an organising principle that captures and coordinates spatial and temporal orientations of ideas and actions connected with power relations. Inherent in the concept is a reference to actors who direct, thereby exercising agency, that is, the culturally constituted capacity to act effectively and intentionally within webs of power relations (Ortner, 2006, pp. 152-153). Thus, the concept of direction signals that ideas and actions are aimed at something specific. Furthermore, following Appadurai (2013, p. 293), we are focusing on various "politics of hope." Appadurai sees the politics of hope in connection with the cultural "capacity to aspire" and wrote that "it is only through some sort of politics of hope that any society or group can envisage a journey to desirable change in the state of things" (Appadurai, 2013, p. 293). Transferred to the context of climate change discourses in Kiribati, the politics of hope point the way from the extreme vulnerability of the atoll state to suitable measures of transformation that promise a secure future based on adaptation and resilience. From this perspective, we will show which politics of hope two successive Kiribati governments have pursued in dealing with the consequences of climate change and which directions I-Kiribati envisage based on their concept of land and imaginations of the future.

The period of time we look at is mainly the one from 2003, when the Kiribati Adaptation Program was launched in the atoll state, to 2017. Between 2009 and 2017, we conducted an annual anthropological field study in Kiribati for about a month each year and, in November 2017, were able to participate in the side event of the Kiribati government at the $23^{\text {rd }}$ Conference of the Parties (COP23) to the United Nations Framework Convention on Climate Change (UNFCCC) in Bonn. In Kiribati we engaged in research with representatives of the state and I-Kiribati citizens of various walks of life on the main atoll of Tarawa and the two outer islands of Nonouti and Onotoa. On these atolls we were also able to talk with people from yet other Kiribati islands. Our field research methods included qualitative interviews in which we gave our interlocutors the opportunity to lead the conversation on a topic we had previously agreed on, so that we could first listen carefully to what they found important. Usually we turned to semi-structured interviewing during the further course of our conversation, when we asked questions we had prepared. We also made use of questionnaires with open-ended questions, to which our respondents were invited to give their answers either in Kiribati language or in English. Additionally, we requested school students to respond to our 
questions in essays. Our partial participation in discourses, participant observation, and analysis of written, audio, and visual sources complemented our methods of data collection.

On the basis of the data we were able to assemble in cooperation with our research participants and the analysis of these and other sources, we will trace the main lines of the policies of two successive governments and discourses of Kiribati's citizens relating to both in situ measures and migration as adaptation strategies.

\section{Cultural concepts of land and the future}

Since climate change news has intruded into their country, I-Kiribati have become even more aware of the fact that their land is precious and vulnerable. In a territorial sense, land for them can mean a piece of land and property, an island, and the whole country. In the context of discourses about climate change consequences, they often describe their land in the Kiribati language as flat or low and small, implicating that it will be threatened by sea-level rise. Importantly, land, te $a b a$, for I-Kiribati also includes social dimensions: of relatives, some of whom are living on the property, of the community inhabiting an island, and of the whole nation. Thus, te $a b a$, with its dual meaning of land/people, has enabled existence on the islands by securing subsistence and conferring political status to owners in the past (cf. Tito et al., 1979, p. 21) and to island communities and the nation in the present. I-Kiribati have always felt closely attached to land/people (cf. Teaiwa, 2015), but in the context of climate change, they emphasise their connection, love, and worries for the land even more (Kempf \& Hermann, 2014, p. 197; Hermann, 2017).

Moreover, the cultural concept of land does not only have a socio-spatial capacity but a temporal dimension as well. In fact, land has historical depth. Pointing to the recent pre-colonial past, I-Kiribati report that their ancestors frequently fought for their pieces of land. Referring to the deeper past and the chain of the Gilbert Islands, some cite myths, according to which the islands were created by Nareau who was considered a god (see Beiabure, Teraku, \& Uriam, 1979; Uriam, 1995). Today, many subscribe to the Christian belief that God created the land. Relating to one or the other (or a combination of these versions), I-Kiribati frequently emphasise that the land was given to them by the creator (cf. Autio, 2010; Camus, 2014). This truth is at times accompanied by the cultural belief that the divine power invested the land with protection that would extend from the past through the present to the future.

Imaginations of the future are shaped nowadays by many discourses. Among them is a culturally specific line of reasoning to the effect that what the future will bring was set in the past. Thinking about the time to come, therefore, necessitates looking at the time past, for it was then that powers set things going which will be realised in the future. In this connection, the Christian God and/or Nareau the 
god (together with spirits) may be cited as powers which determined the course of events. However, the cultural concept of the future does not only include temporal dimensions but also a spatial component. The anticipation of what will come is usually linked to the expectation that land will be there for the collectivity and Kiribati culture. Therefore, land plays a crucial role in imaginations of the future. As the foundation of Kiribati people in ancestral times, it has always been known to secure life for the next generations. Thus, the cultural concepts of land and the future are closely linked in Kiribati. Additional discourses influencing I-Kiribati's imaginations of the future comprise not only formations of statements about the continuation of life, society, culture, and development, but also talk about likely impacts of climate change and sea-level rise.

Discourses about projections by the climate sciences regarding the risks to which land and people will be exposed by climate change consequences have exerted a powerful influence on I-Kiribati's outlook as they claim to represent truths about the country's future (Hermann \& Kempf, 2018, pp. 21-23). Formations of statements to the effect that Kiribati's low-lying atolls will be exposed more often to inundation and might become uninhabitable for the majority of the population in only a few decades have especially caused Kiribati's political decision-makers and many of its citizens to take a stand. Depending on the extent to which representatives of Kiribati's governments and people have accepted the climate sciences' truths, they have included respective projections in their imaginations of the country's future to varying degrees and devised their short-, medium-, and long-term plans for in situ adaptation and migration accordingly.

\section{Government policies on adaptation}

Since the 1990s, when the various Kiribati governments began to be increasingly confronted with discourses on the possible negative consequences of climate change, they have striven to protect land, inhabitants, and nation through adaptation measures. The development and application of appropriate forms of adaptation in the sense of reducing vulnerability and increasing resilience (Finan, 2009, p. 177) present local institutions with complex tasks that include political, social, and cultural dimensions, in addition to technical and economic challenges (Fiske et al., 2014, pp. 41-50). In Kiribati, measures to adapt to the possible impacts of climate change have been associated with different spatial and temporal orientations, focal points, discourses, and projects. A brief genealogy of the political praxis of various Kiribati governments that were confronted with the challenges of climate change will provide information about the directions taken with regard to adaptation.

Teburoro Tito was Kiribati's first president to develop policy responses to global warming, climate change, and sea-level rise. During his term in office (1994 2003), Kiribati ratified the UNFCCC and established a National Climate Change Study Team. In 1999, Kiribati presented its Initial Communication under the 
UNFCCC (Kiribati Government Ministry of Environment and Social Development, 1999). The report outlined the vulnerability of the atoll state and specified the need for adaptation measures in the areas of coastal infrastructure, water resources, agricultural systems, health, and fisheries. In subsequent years, the World Bank implemented the KAP, a million-dollar, country-specific pilot project on adaptation to climate change with funding from the Global Environmental Facility, the Government of Australia, the Japan Policy and Human Resources Development Fund, NZAID, other development partners, and the Government of Kiribati (see e.g. Storey \& Hunter, 2010; Prance, 2016).

In 2003 Anote Tong took over the presidency. From the perspective of the government under President Anote Tong, who was in office until 2016, global warming and climate change impacts posed existential threats to the future of Kiribati. Tong underscored the will of his government to preserve homeland and sovereignty under all circumstances in his speeches on the international political stage (see e.g. Tong, 2008). He linked his appeals for mitigation of greenhouse gas emissions worldwide with the request to support particularly vulnerable atoll states such as Kiribati in the adaptation measures necessary. During his presidency, Tong gave high priority to adaptation. The implementation of the various phases of $\mathrm{KAP}^{1}$ was intended to facilitate the mainstreaming of adaptation into national economic planning and was designed for the long term. The priorities included raising awareness among the population, protecting drinking water resources and coastal areas, and securing local infrastructure (see Ministry of Environment, Lands and Agricultural Development, 2013). Coastal protection measures included, for example, the construction of seawalls and the planting of mangroves. As a supplement to the KAP, the Tong government initiated the Kiribati National Adaptation Program of Action (NAPA) in 2004, which was tailored to urgent adaptation needs (Government of Kiribati, 2007). Finally, in 2014, the Tong government took the step of purchasing a large piece of land in Fiji, the Natoavatu Estate, thereby securing resources outside Kiribati in order to ensure the economic development and future food security of the atoll state (see Hermann \& Kempf, 2017).

The current government under President Taneti Maamau, which has been in office since March 2016, aims to improve prosperity, infrastructure, security, and governance. The vulnerability of the atoll state to the effects of climate change is seen as a serious constraint on the way to achieving the intended upswing. The Maamau government, therefore, emphasises the need to include adaptation and mitigation measures to minimise risks and achieve the desired development goals. With its two-decade development plan "Kiribati Vision 20" (KV20), it seeks to combine economic and social progress with adaptation to climate change to preserve land, culture, and identity for the future. A building block of the development program is land reclamation on South Tarawa (Temaiku, Bikenibeu, Bairiki,

1 The KAP comprised three phases: Phase I: Preparation (2003-2005), Phase II: Pilot Implementation (2006-2011), Phase III: Expansion (2012-2018) (see Republic of Kiribati, n.d., and The World Bank, 2019). 
Betio, and areas in the lagoon) and on Kiritimati. The aim is to counter population growth, land scarcity, and climate change impacts (Government of the Republic of Kiribati, 2016, p. 20). The so-called Temaiku Adaptation Project is presented in a video clip which the Kiribati government produced for a side event at the UN Climate Change Conference (COP23) in Bonn in November 2017:

Temaiku is a large, low-lying, uninhabitable government land and this initiative aims to elevate the land and make it habitable. The plan is to have up to 35,000 people reside on this piece of land and essential facilities, such as schools, clinics and shops, will also be built. The town planning of this area will be designed in a way that is resilient to the impacts of climate change. ${ }^{2}$

With this policy of in situ adaptation, which promises the long-term expansion and preservation of land, the government associates a politics of hope. The extent to which this policy is interwoven with Christian convictions can be seen in President Maamau's response to scientific projections that large parts of the atoll state will be flooded in the future by the progressive rise in sea levels. He is of the opinion that God will protect the land and will not give it up in any way:

Climate change is indeed a serious problem to Kiribati, but we don't believe that Kiribati will sink like a Titanic ship. The Titanic ship is different. It is built by buman hands while our country, our beautiful islands, are created by the hands of God. ${ }^{3}$

This politics of hope is based on the confidence that the country and the future are stable. And although the current Kiribati government is thus explicitly trying to distinguish itself from the previous government under Anote Tong and its plans for the future, which are perceived as too pessimistic, there are at the same time a whole series of political continuities. The former Tong government had already considered elevating Temaiku and developing it as a new settlement area but had to postpone the project because of a lack of financial support (Uan \& Anderson, 2014 , p. 243). The current Kiribati government has also taken up and pursued key elements of climate change policy from the Tong era. ${ }^{4}$ These include the extension of the final phase of the KAP III project until the end of 2018 as well as looking after the land in Fiji, which is primarily regarded as an investment and continues to be earmarked for the cultivation of food (see Te Uekera, 2019, p. 3).

The brief historical outline shows a sequence of governments in the atoll state of Kiribati that, over a period of more than two decades, have been focusing on in situ adaptation in dealing with climate change issues. Each new government resort-

\footnotetext{
2 Transcript from the video clip "Kiribati Vision 20 in the face of Climate Change," Government of the Republic of Kiribati, COP23 Side-Event, November 16, 2017. See also Jacobs (2018).

${ }^{3}$ Transcript from the video clip "Kiribati Vision 20 in the face of Climate Change," Government of the Republic of Kiribati, COP23 Side-Event, November 16, 2017.

4 These include the "Kiribati Joint Implementation Plan for Climate Change and Disaster Risk Management" (2014), the "Whole of Island Approach" (2016), the "Integrated Vulnerability Assessment Framework for Atoll Islands" (2016), and the "Kiribati Adaptation Program (KAP) III." See also Government of the Republic of Kiribati (2016, p. 45).
} 
ed to political guidelines, projects, and programs of the previous government, continued these projects, and sought to set its own course within the framework of the adopted directions. The political concern to link land and future with the hope of preservation and continuation is foregrounded in this prioritisation of adaptation.

\section{$4 \quad$ Government policies on migration}

Two contrary directions of climate change policy discourses and practices can be discerned in Kiribati regarding the question of migration as a form of adaptation to climate change. This divergence is based essentially on the political orientations of the governments under Tong and Maamau. The current Maamau government attaches great importance to staying in Kiribati. Since the majority of the I-Kiribati are also in favour of remaining in the country, the government knows the greater part of the population is behind it when it focuses on the territory of Kiribati. The Maamau government rules out a complete loss of the country in the long term as well as climate-induced collective relocation. By contrast, in view of the scientific projections of the future consequences of climate change, the previous government under Tong saw itself as responsible for preparing the population for the worst case of a largely uninhabitable atoll state in the long term.

The government under Anote Tong had a clear political orientation. Measures to adapt to climate change in the Kiribati islands were very important from their point of view and were implemented wherever possible. However, the then government also made it clear that in situ adaptation measures on narrow, low-lying atolls without alternative possibilities quickly reached their natural limits. At no time did the Tong government move away from the demands on the industrialised countries to make greater efforts in the area of mitigation. At the same time, it assumed that even a rapid and significant reduction in greenhouse gases could no longer reverse the process of climate change already underway and the resulting threat to Kiribati. In this respect, mitigation and in situ adaptation in the Tong era were only seen as short- to medium-term responses to the challenges posed by climate change. In the long term, the Tong government felt it had a duty to prepare the country's inhabitants to migrate voluntarily and with dignity. Vocational qualification measures were, therefore, the central prerequisite for this strategy. Well-trained I-Kiribati should help to cover the need for labour in certain areas, such as the nursing professions, in order to be accepted in the metropolitan states of the region and to be able to bring family members from Kiribati to their new country of residence if possible (cf. Farbotko, Stratford, \& Lazrus, 2016; Klepp \& Herbeck, 2016).

The politics of hope under the Tong government aimed to ensure that the people could remain in the atoll state for as long as possible. For the future - beyond the envisaged period of 50-60 years - Tong prudently envisaged emigration and the survival of I-Kiribati in the diaspora. Under the present Maamau govern- 
ment, this political strategy of 'migration with dignity' as a forward-looking form of adaptation to the negative consequences of climate change no longer plays a significant role. President Maamau and his government are currently focusing on the need to improve general living conditions: "The core themes are increasing the wealth, the health and the education of our people so that they can look after themselves in a dignified manner" (HE Taneti Maamau, Interview, November 17, 2017). Here, the aspect of dignity is above all linked to upswing and progress. Both should benefit the broad population in the country. The associated politics of hope points particularly in one direction:

[I-Kiribati] don't believe in their islands sinking. It is an insult to them. They say: "We have been here for ages and ages and now you are telling us [he pauses]. No!" It's all about that. ... But anyway. It is quite a difficult prediction to be sure about, but we bope - myself, my God and my people are working towards a common destination: Staying in Kiribati. (HE Taneti Maamau, Interview November 17, 2017)

The general direction that the Maamau government seeks to give to the mobility of its citizens is that of returning to their land or their own country. On the one hand, this concerns the political plan to counter the rural exodus to and population growth on South Tarawa. ${ }^{5}$ The background for this is the fact that almost half of the island state's population, estimated at about 110,000 people, currently live on the main atoll Tarawa (see The World Factbook, 2019). For this reason, the Maamau government is using economic incentives to encourage a larger number of people to return to the outer islands. The orientation to one's own land gives the direction here. On the other hand, the current government promotes temporary international labour mobility in order to improve the economic situation of the population in Kiribati in general. The political-economic calculation is based on remittances but, above all, on returning migrant workers who invest their money earned abroad in Kiribati. The return to the home country of Kiribati is a decisive factor here.

The Maamau government generally distinguishes international 'mobility' in the sense of labour and return mobility from international 'migration', a term used more in the sense of emigration. An international migration of I-Kiribati is considered pragmatically by the Maamau government against the background of a growing indigenous population. No one should be prevented from emigrating. Nevertheless, the current government does not formulate a political strategy that establishes a necessary link between migration, climate change, and the future. Rather, the politics of hope is aimed at enabling people to stay in the country in the long term.

There are both similarities and differences regarding migration policy under the Tong and Maamau governments. Both governments wanted to ensure that the

5 On rural-urban migration see Uan and Anderson (2014, p. 242) and Van Trease (1993, pp. 138141). 
population remains in the country in the short and medium term. In view of the future uninhabitability of the atolls caused by the consequences of climate change, the Tong government viewed migration and resettlement as the only viable way out in the long term. By contrast, the Maamau government established a new policy of remaining in Kiribati and seeks to de-emphasise the discourse on migration that was dominant under its predecessor. With this policy, it ties in with cultural conceptualisations of land and the future, on the basis of which it follows the way towards adaptation, continuity, and security in the context of future threats from climate change impacts.

\section{$5 \quad$ Local discourses on adaptation}

Government policies on adaptation to climate change and accompanying campaigns have left an imprint on Kiribati's citizens' awareness of projections for the future and possibilities to act. In addition, I-Kiribati have learned about climate change issues from discourses of transnationally outreaching overseas churches and their own churches (Kempf, 2012) as well as from representatives of NGOs and I-Kiribati activists. As I-Kiribati have interwoven strands of these discourses with discursive formations about their land and the future, they have developed a heterogeneity of attitudes towards adaptation. There are those who do not see the need for adaptation because they do not believe that climate change will affect their home country in the immediate future. Among those who would deal with the consequences, there are some who would not consider adaptation measures because they claim they have not enough know-how and resources at their disposal. Others would doubt the effectiveness of these measures. By contrast, there are experts, activists, and a number of people who have been involved in activities such as building coastal protection or planting mangroves and are keen to promote adaptation measures. There are also many I-Kiribati who, when questioned, express their will to do whatever they can to protect their beloved land and home country from the severe impacts of climate change. One measure that is often mentioned is the construction of sea walls (te bono). ${ }^{6}$ A quote from a 17-year-old woman from the atoll of Arorae illustrates this view:

If Kiribati is affected by climate change, I think that I will seek ways that will affect Kiribati [in a positive way]. And we will stay on our land and will not leave our land, but we will try to face the problem of climate change. And we should build sea walls at the edge of the sea. Like our ancestors said: "The place where we are born, we are happy to die there as well." (September 14, 2010; translated from the Kiribati language)

I-Kiribati also frequently point to the planting of mangroves (te tongo) as a measure of coastal protection. As a girl from Nikunau Island, aged 15, explained:

${ }^{6}$ For an assessment of coastal protection structures on Kiribati's main atoll Tarawa, see Duvat (2013). 
It will be necessary for us to plant plants and not to cut them, just like the mangrove which is the tree in the sea. Te tongo means mangrove in our own language. This prevents the erosion. (October 8, 2013)7

The numerous statements I-Kiribati have made during the past decade on their will to take adaptation measures largely resemble each other. While many of Kiribati's citizens emphasise the building of sea walls and planting of mangroves, some people know that mangroves are to be preferred to sea walls since the latter may even contribute to coastal erosion. In addition, some people also draw attention to the need to take measures of environmental protection, such as cleaning the coast of rubbish that may obstruct coastal vegetation and not taking sand from the beach for construction purposes. What local discourses have so far not picked up to a significant extent are plans by the successive governments of elevating a certain area and developing it $-\mathrm{a}$ fact that suggests these plans are predominantly discussed in government circles. But with respect to the other adaptation measures I-Kiribati mention, it is obvious that they put into practice what they are talking about. This can be seen especially on urban South Tarawa, part of the main atoll, and also here and there on the outer atolls. In some places, stones have been piled up to form sea walls. At a few places people also erected te bwibwi, constructions for coastal protection that consist basically of vertical sticks and coconut leaves plus other organic material put between them horizontally. ${ }^{8}$ At other places, people have begun to plant mangroves, following the example and encouragement of government, NGOs, and other initiatives.

Local discourses on the preparedness and the implementation of adaptation measures shine a light on a majority of Kiribati's citizens' sense of direction: They orient themselves in socio-spatial and socio-temporal terms towards their beloved land of Kiribati. Statements of their refusal to leave their country, their will to stay and adapt are clearly based on their cultural concept of land, promising the continuation of collectivity and culture. Based on this concept, many say their future lies here, in Kiribati. A few, however, add that this may only hold for the immediate years to come.

\section{$6 \quad$ Local discourses on migration}

Whereas a broad consensus exists in the atoll state regarding the need for in situ adaptation to climate-related changes of the environment, there is disagreement about international migration as a response to climate change consequences and the need for international relocation in the future. As the I-Kiribati feel deeply attached to their land, the dominant discourse in this context has the effect of

\footnotetext{
7 This and the following quotations that were given in English, were slightly edited to aid readability.

${ }^{8}$ Neemia Mackenzie listed te bwibwi as among the "traditional methods of creating accretions" and wrote that people thought te bwibwi are no longer working (Neemia Mackenzie, 2004, p. 36).
} 
them staying in the country and refusing to emigrate. I-Kiribati author Linda Uan and John Anderson found in a national survey they conducted in 2011 that the "majority of I-Kiribati (65 per cent) have no wish to live in another country" (Uan \& Anderson, 2014, p. 247). Staying on their land does not exclude internal mobility between the islands of Kiribati, since this kind of movement enables them to keep their relationships to the land alive. By contrast, international emigration for I-Kiribati carries the risk of weakening their connections to their land, culture, and identity, which is why it is debated controversially.

International temporary mobility for the purpose of education and labour (particularly seasonal work) is looked on favourably by many citizens of Kiribati, because both types of migration have the advantage of securing return to their home country. But people rarely express any thoughts about labour mobility as a way out from the climate change consequences in their home country. Many among the minority that does consider international migration with a view to climate projections insist that all other measures of mitigating or adapting to climate change need to be considered first before they would leave for overseas. A number of such measures were detailed by a 17-year-old woman from the atoll of Nikunau who explained what she would do if Kiribati was affected by climate change:

1) Ask for assistance from overseas countries to provide means/ways to belp the people of Kiribati; for example, foreign aid. 2) Educate more young people about the changing climate so that they can be aware of the consequences that might be faced by the I-Kiribati. 3) If the government sends its people to places where they can find jobs and become citizens in that particular country, for example, New Zealand and Australia. 4) The government should encourage local people to get their children educated so that they know what our island is going through, for example, rising sea levels. (September 14, 2010)

Tellingly, she talked about international migration only as the third option, using a conditional clause with reference to the need of the government making it possible. Her expectation that the government will lay the groundwork for labour mobility and immigration to one of the metropolitan states in the South Pacific resembles other statements of I-Kiribati that resonate well with the migration policy of the Tong government. However, similar voices have sometimes been heard, especially among the youth, since the government under President Maamau has come to power. In addition, there have been I-Kiribati then and now who apply for work overseas. But again, the reasons for this are of an economic nature and only in very rare cases because of the threat from climate change.

International migration and even relocation with a view to projected consequences from climate change came to be imaginable by some I-Kiribati when news arrived in 2012 that the Kiribati government under President Tong was conducting negotiations on the purchase of a large freehold estate in Fiji. A few people were aware of their government's statements making it clear that the land was meant to provide future food security. But others concluded that the Tong government must be interested in the estate with climate change-induced migration in mind. 
While they too emphasised their close attachment to their land, they thought that, when the worse came to the worst, migration and even relocation to this estate in Fiji would be the option to choose. As one middle-aged interlocutor from the southern atoll of Nonouti told us, referring to some of his compatriots' opinions:

Now when they heard that the Kiribati Government had land in Fiji, some people said: "So it's better we go and live there!" But not all agreed. Some [said]: "Ah! We can't go, we must stay!' (September 23, 2012)

As for himself, he said that when the rising sea threatened atoll life, he would want to immigrate with his family to Fiji. Others equally began imagining migration to what became known as Kiribati's land in Fiji in the run-up to and after the purchase. A couple of years later, a few I-Kiribati still mention it as a safe haven with a view to a worst-case scenario. And even when interlocutors insist, nowadays, that they would stay in Kiribati even though their former government had bought this estate, their statements suggest that they associate this land with migration.

When international migration is brought up by a minority of Kiribati's citizens as a last resort in the face of climate change, it is often imagined in connection with a place the I-Kiribati would need for themselves. This is evident in the response of a young I-Kiribati from Tarawa when responding to the question of how she sees her future:

In my future, I would like all the people in Kiribati to find their places overseas or be sent overseas to live there because of coastal erosion that happened due to climate change. (September 13, 2017)

Her voice joins those who say that they would prefer a collective relocation rather than an individual one when forced by the adverse effects of climate change. Even if it seems otherwise at first glance, such a thought of collective relocation is firmly built on the cultural concept of land. Since land and people are conceived of culturally as forming an entity, it is only logical that the collective would have to move and merge with the new land if one day the atolls were no longer able to hold their ground in the face of climate change. Culturally shaped imaginations of the future similarly play an important role in weighing the pros and cons of emigration. As the future harbours a spatial component, there should be land for the people of Kiribati somewhere.

\section{$7 \quad$ Conclusion}

Since the scientific discourse on anthropogenic climate change found its way to Kiribati, governments and citizens of the atoll state have been negotiating the possibilities of adaptation within the framework of their historical and cultural conceptualisations of land and their specific imaginations of the future. With the dominant narratives about climate change, the negative effects of which are said to be of 
long-term existential significance for the particularly vulnerable Kiribati, the question arose as to which direction to take in order to regain and maintain the ontological security that had long been common in this part of the Pacific region. The concept of direction helps us to understand the local notions of land and the future as spatial and temporal modalities of orientation, which can be discerned in I-Kiribati discourses on adaptation to the consequences of climate change. We also include in our perspective the directions of hope as part of the political practice of both grassroots I-Kiribati and the political elites of the atoll state. Here, the ability to set priorities with regard to adaptation and migration forms the basis of a politics of hope that claims to outline the directions in relation to land and the future. It becomes apparent that local views, practices, and policies regarding adaptation as a form of making the links between land and people resilient and, thus, sustainable diverge, in that both continuities and breaks are promised. The question of migration plays a central role in this discursive field of divergent horizons of hope.

A genealogy of projects on in situ adaptation in Kiribati makes it clear how much successive governments depended on the political preparatory work of their predecessors. Under the current Maamau government, as under the previous governments, the preservation of drinking water reserves and food security as well as the fortification, consolidation, and development of land are aimed at adapting to the future impacts of climate change. The politics of hope shows its continuity above all in the political will of both the Tong and the Maamau governments to guarantee the continuity of land, people, and the future as the spatial and temporal foundation of ontological security for the local population. Dissonance and divergence arise in terms of long-term perspectives when the current govemment contrasts its vision of resilience, integrity, and continuity of land and people with the previous political discourse of loss, rupture, displacement, and migration from the Tong era. Thus, the cultural conception of land and imaginations of the future contribute to that current politics of hope, which de-emphasises migration and diaspora especially as a means of adaptation to climate change and, instead, reclaims land, belonging, and the future in Kiribati.

The majority of local discourses on adaptation and migration also point in a direction that locates land, community, and the future in Kiribati. The unbroken will of many I-Kiribati to remain in the country and their willingness to actively support adaptation measures are closely related to the cultural conviction that the land and its people have always been blessed with a future. And even when a minority of I-Kiribati associate the purchase of land in Fiji with migration, indigenous preferences towards collective relocation, national refuge, and attributions of a forward-looking politics of hope to policy makers suggest that these imaginations are guided by cultural notions of land and the future. 


\section{Acknowledgements}

We wish to express our deep gratitude to all who welcomed us in Kiribati and to our many interlocutors, including representatives of national and local governments, friends, and adopted relatives, who cooperated in our research. Our many thanks and appreciation go to the successive governments of Kiribati for granting us research visas and the local governments of the islands we visited for providing on-the-ground support. Our thanks also go to Carola Klöck and Michael Fink for inviting us to the workshop from which this volume emerged and for their constructive comments on our contribution.

\section{Bibliography}

Appadurai, A. (2013). The future as cultural fact: Essays on the global condition. London and New York: Verso Books.

Autio, P. M. (2010). Hard custom, hard dance: Social organisation, (un)differentiation and notions of power in a Tabiteuean community, Southern Kiribati. Helsinki: Helsinki University Press.

Barnett, J. (2017). The dilemmas of normalising losses from climate change: Towards hope for Pacific atoll countries. Asia Pacific Viewpoint, 58(1), 3-13.

Barnett, J., \& Adger, N. W. (2003). Climate dangers and atoll countries. Climatic Change, 61(3), 321-337.

Barnett, J., \& Campbell, J. (2010). Climate change and small island states: Power, knowledge and the South Pacific. London and Washington, DC: Earthscan.

Barnett, J., \& Chamberlain, N. (2010). Migration as climate change adaptation: implications for the Pacific. In B. Burson (Ed.), Climate change and migration: South Pacific perspectives (pp. 51-60). Wellington: Institute of Policy Studies.

Barnett, J., \& O’Neill, S. J. (2012). Islands, resettlement and adaptation. Nature Climate Change, 2, 8-10.

Barnett, J., \& Webber, M. (2010). Migration as adaptation: Opportunities and limits. In J. McAdam (Ed.), Climate change and displacement: Multidisciplinary perspectives (pp. 37-55). Oxford and Portland: Hart Publishing.

Beiabure, M., Teraku, T., \& Uriam, K. (1979). Creation: The work of the gods. In A. Talu et al. (Eds.), Kiribati: Aspects of history (1984 ed., pp. 1-6). Suva and Tarawa: IPS Extension Services and Ministry of Education, Training and Culture.

Betzold, C. (2015). Adapting to climate change in Small Island Developing States. Climatic Change, 133(3), 481-489.

Betzold, C. (2016). Aid and adaptation to climate change in Pacific Island countries. Crawford School of Public Policy, ANU (Development Policy Centre Discussion Paper No. 46). Canberra. 
Campbell, J. (2010a). Climate change and population movement in Pacific Island Countries. In B. Burson (Ed.), Climate change and migration: South Pacific perspectives (pp. 29-50). Wellington: Institute of Policy Studies.

Campbell, J. (2010b). Climate-induced community relocation in the Pacific: The meaning and importance of land. In J. McAdam (Ed.), Climate change and displacement: Multidisciplinary perspectives (pp. 57-79). Oxford and Portland: Hart Publishing.

Campbell, J., \& Bedford, R. (2014). Migration and climate change in Oceania. In E. Piguet \& F. Laczko (Eds.), People on the move in a changing climate: The regional impact of environmental change on migration (pp. 177-204). Dordrecht: Springer.

Camus, G. (2014). Tabitenea: Kiribati. Geneva: Fondation culturelle Musée BarbierMueller.

Duvat, V. (2013). Coastal protection structures in Tarawa Atoll, Republic of Kiribati. Sustainability Science, 8(3), 363-379.

Farbotko, C., Stratford, E., \& Lazrus, H. (2016). Climate migrants and new identities? The geopolitics of embracing or rejecting mobility. Social and Cultural Geography, 17(4), 533-552.

Finan, T. (2009). Storm warnings: The role of anthropology in adapting to sea-level rise in southwestern Bangladesh. In S. A. Crate \& M. Nuttall (Eds.), Anthropology and climate change: From encounters to actions (pp. 175-185). Walnut Creek, CA: Left Coast Press.

Fiske, S. J., Crate, S. A., Crumley, C. L., Galvin, K., Lazrus, H., Lucero, L., ... Wilk, R. R. (2014). Changing the atmosphere: Anthropology and climate change. Final report of the AAA Global Climate Change Task Force. Arlington, VA: American Anthropological Association.

Government of Kiribati. (2007). National adaptation program of action (Napa). Environment and Conservation Division, Ministry of Environment, Land, and Agricultural Development. Tarawa. Retrieved from https://www.adaptationundp.org/sites/default/files/downloads/kiribati_napa_.pdf.

Government of the Republic of Kiribati. (2013). Kiribati integrated emvironment policy: Coordinated by Environment and Conservation Division (ECD) of Ministry of Environment, Lands and Agriculture Development. Tarawa. Retrieved from https://www.sprep.org/attachments/VirLib/Kiribati/KIEP.pdf.

Government of the Republic of Kiribati. (2016). Kiribati 20-Year Vision 2016-2036: KV20. Tobwaan ao Karikirakean Kiribati. Tarawa. Retrieved from http://www.mfed.gov.ki/sites/default/files/KIRIBATI\%2020-YEAR\%20VI SION\%202016-2036\%20.pdf.

Hermann, E. (2017). Climate change and worries over land: Articulations in the atoll state of Kiribati. In E. Dürr \& A. Pascht (Eds.), Emvironmental transformations and cultural responses: Ontologies, discourses, and practices in Oceania (pp. 49-73). New York: Palgrave Macmillan. 
Hermann, E., \& Kempf, W. (2017). Climate change and the imagining of migration: Emerging discourses on Kiribati's land purchase in Fiji. The Contemporary Pacific, 29(2), 231-263.

Hermann, E., \& Kempf, W. (2018). 'Prophecy from the Past': Climate change discourse, song culture and emotions in Kiribati. In T. Crook \& P. RudiakGould (Eds.), Pacific climate cultures: Living climate change in Oceania (pp. 21-33). Warsaw and Berlin: De Gruyter Open.

Jacobs. (2018). Jacobs presents sea level rise strategy at United Nations climate change conference. Retrieved from http://www.jacobs.com/news/106/jacobs-presentssea-level-rise-strategy-at-united-nations-climate-change-conference.

Kempf, W. (2009). A sea of environmental refugees? Oceania in an age of climate change. In E. Hermann, K. Klenke, \& M. Dickhardt (Eds.), Form, Macht, Differenz: Motive und Felder ethnologischen Forschens (pp. 191-205). Göttingen: Göttingen University Press.

Kempf, W. (2012). Climate change, migration, and Christianity in Oceania. In K. Hastrup \& K. Fog Olwig (Eds.), Climate change and buman mobility: Global challenges to the social sciences (pp. 235-257). Cambridge: Cambridge University Press.

Kempf, W. (2017). Climate change, Christian religion and songs: Revisiting the Noah story in the Central Pacific. In E. Dürr \& A. Pascht (Eds.), Environmental transformations and cultural responses: Ontologies, discourses, and practices in Oceania (pp. 19-48). New York: Palgrave Macmillan.

Kempf, W., \& Hermann, E. (2014). Epilogue. Uncertain futures of belonging: Consequences of climate change and sea level rise in Oceania. In E. Hermann, T. van Meijl, \& W. Kempf (Eds.), Belonging in Oceania: Movement, place-making and multiple identifications (pp. 189-213). Oxford: Berghahn.

Kinnvall, C., \& Mitzen, J. (2017). An introduction to the special issue: Ontological securities in world politics. Cooperation and Conflict, 52(1), 3-11.

Kiribati Government Ministry of Environment and Social Development. (1999). Initial communication under the United Nations Framework Convention on Climate Change. Tarawa. Retrieved from https://unfccc.int/resource/docs/natc/ kirnc1.pdf.

Klepp, S., \& Herbeck, J. (2016). The politics of environmental migration and climate justice in the Pacific region. Journal of Human Rights and the Environment, 7(1), 54-73.

Lazrus, H. (2012). Sea change: Island communities and climate change. Annual Review of Anthropology, 41, 285-301.

Ministry of Environment, Lands and Agricultural Development. (2013). Second communication under the United Nations Framework Convention on Climate Change. Tarawa. Retrieved from https://unfccc.int/resource/docs/natc/kirnc2.pdf.

Mortreux, C., \& Barnett, J. (2009). Climate change, migration and adaptation in Funafuti, Tuvalu. Global Environmental Change, 19, 105-112. 
Neemia, U., \& Thaman, R. (1993). The environment and sustainable development. In H. van Trease (Ed.), Atoll politics: The Republic of Kiribati (pp. 285-301). Christchurch and Suva: Macmillan Brown Center for Pacific Studies and Institute of Pacific Studies, USP.

Neemia Mackenzie, U. (2004). 'The Sun Has Come Down Closer to My Island': People's perceptions of climate change. A Social Assessment Report. Tarawa.

Nunn, P. D. (2009). Responding to the challenges of climate change in the Pacific Islands: Management and technological imperatives. Climate Research, 40, 211-231.

Nurse, L. A., McLean, R. F., Agard, J., Briguglio, L. P., Duvat-Magnan, V., Pelesikoti, N., ... Webb, A. (2014). Small islands. In V. R. Barros, C. B. Field, D. J. Dokken, M. D. Mastrandrea, K. J. Mach, T. E. Bilir, ... L. L. White (Eds.), Climate Change 2014: Impacts, adaptation, and vulnerability. Part B: Regional aspects: Contribution of Working Group II to the Fifth Assessment Report of the Intergovernmental Panel on Climate Change (pp. 1613-1654). Cambridge: Cambridge University Press.

Ortner, S. B. (2006). Anthropology and social theory: Culture, power, and the acting subject. Durham: Duke University Press.

Prance, F. (2016). Indigenous ontologies and developmentalism: Analysis of the national consultations for the Kiribati Adaptation Program. In J. P. Marshall \& L. H. Connor (Eds.), Environmental change and the world's futures: Ecologies, ontologies and mythologies (pp. 113-128). New York: Routledge.

Republic of Kiribati. (n.d.). Climate change - Kiribati Adaptation Program (KAP). Retrieved from http://www.climate.gov.ki/kiribati-adaptation-program/.

Storey, D., \& Hunter, S. (2010). Kiribati: An environmental 'perfect storm'. Australian Geographer, 41(2), 167-181.

Teaiwa, K. M. (2015). Consuming Ocean Island: Stories of people and phosphate from Banaba. Bloomington and Indianapolis: Indiana University Press.

Te Uekera. (2019). Moanna $\mathrm{n}$ taubobonga babaire ibukin kabonganaan aban Kiribati are i Biti [Beginning of decision making on the use of the Kiribati land in Fiji]. No. 17 (April 25), p. 3.

The World Bank (2019). Kiribati - Third phase of Kiribati Adaptation Program Project. Retrieved from http://documents.worldbank.org/curated/en/100741 561139747493/Kiribati-Third-Phase-of-Kiribati-Adaptation-Program-Project.

The World Factbook. (2019). Kiribati. Washington DC: Central Intelligence Agency. Retrieved from https://www.cia.gov/-library/publications/the-worldfactbook/geos $/ \mathrm{kr} \cdot \mathrm{html}$.

Tito, K., Tiata, T., Teanako, B., Fakaofo, U., \& Tautau, A. (1979). Tradition: Ancient Gilbertese society. In A. Talu et al. (Ed.), Kiribati: Aspects of history (1984 ed., pp. 12-28). Suva and Tarawa: IPS Extension Services and Ministry of Education, Training and Culture.

Tong, A. (2008). Statement by His Excellency Anote Tong, President of the Republic of Kiribati: The General Debate of the 63rd Session of the United 
Nations General Assembly. Retrieved from https://www.un.org/en/ga/63/ generaldebate/pdf/kiribati_en.pdf.

Uan, L., \& Anderson, J. (2014). Climate displacement and Kiribati: Notes from the frontline. In S. Leckie (Ed.), Land solutions for climate displacements (pp. 228-250). London and New York: Routledge.

Uriam, K. K. (1995). In their own words: History and society in Gilbertese oral tradition. Canberra: The Journal of Pacific History.

Van Trease, H. (1993). South Tarawa case study. In H. van Trease (Ed.), Atoll politics: The Republic of Kiribati (pp. 125-157). Christchurch and Suva: Macmillan Brown Center for Pacific Studies and Institute of Pacific Studies, USP. 